\title{
Multipath Routing protocol: NCPR and QAMR
}

Roopali Garg,Guneet Kaur

Co-ordinator,deptt of IT,UIET, Panjab University, Chandigarh

roopali.garg@gmail.com

Research Scholar, deptt of IT,UIET, Panjab University, Chandigarh

\section{ABSTRACT}

gunu_dhingra@yahoo.co.in

Mobile ad hoc network is an assembly of mobile nodes with no centralized server. Due to mobility of nodes and decentralized network it is difficult to maintain the quality of service (QoS) in routing the packets from source to destination. QoS can be defined in terms of various metrics like delay, bandwidth, packet loss, routing overhead, jitter. Routing can be unicast, multicast or multipath. This paper presents the description about the QoS multipath routing algorithm.

\section{Indexing terms/Keywords}

MANET- Mobile Ad hoc Network; QoS- Quality of service; QAMR- QoS enabled ant colony optimization based multipath routing protocol; NCPR- neighbor coverage based probabilistic rebroadcast protocol.

\section{Council for Innovative Research}

Peer Review Research Publishing System

Journal: INTERNATIONAL JOURNAL OF COMPUTERS \& TECHNOLOGY

\author{
Vol 11, No.10 \\ editor@cirworld.com \\ www.cirworld.com, member.cirworld.com
}




\section{INTRODUCTION}

Mobile ad hoc network[1][2] is a decentralized network. Decentralized network is the one which has no central servers unlike centralized client server model. In mobile ad hoc networks, nodes have dynamic movement. Mobile nodes are connected via radio waves. Nodes can be any device like mobiles or laptops and they are free to move.

MANET is a type of ad hoc network[3]. Ad hoc networks are of two types: static and dynamic. Dynamic ad hoc networks are also known as mobile ad hoc networks. Mobile ad hoc network donot have any fixed infrastructure. Nodes communicate with each other directly or through intermediate nodes. In mobile AD HOC networks a node can act both as a host or a router. Because of the dynamic nature of nodes routing is a challenging issue in mobile ad hoc network.

Multiple paths could be found from a source to destination using these protocols. To find multiple paths is beneficial in case of link breakages. Link breakages could be frequent in mobile ad hoc network because of mobility of nodes. So it is very difficult to maintain QoS.

Qos routing is a routing process which assures a support to a set of QoS parameters while the establishment of a route. QoS routing is of great importance in real time applications in the real time applications QoS is required over the entire multi-hop path. An applications requirements of QOS can be fulfilled using link constraints or path constraints[4]. Path constraints refer to fulfilling the QOS requirement of end to end delay on a single path. For link constraints there are various parameters connected like (1) additive constraint (2) concave/ convex constraints (3) multiplicative constraints.[5]

Mobile ad hoc networks use several protocols for routing. The routing protocols for mobile ad hoc networks are classified into

(1) Table driven protocols[6]

(2) On-demand routing protocols.[7],[8]

Several On demand routing protocols are dynamic source routing [9][10] , ad hoc on demand distance vector

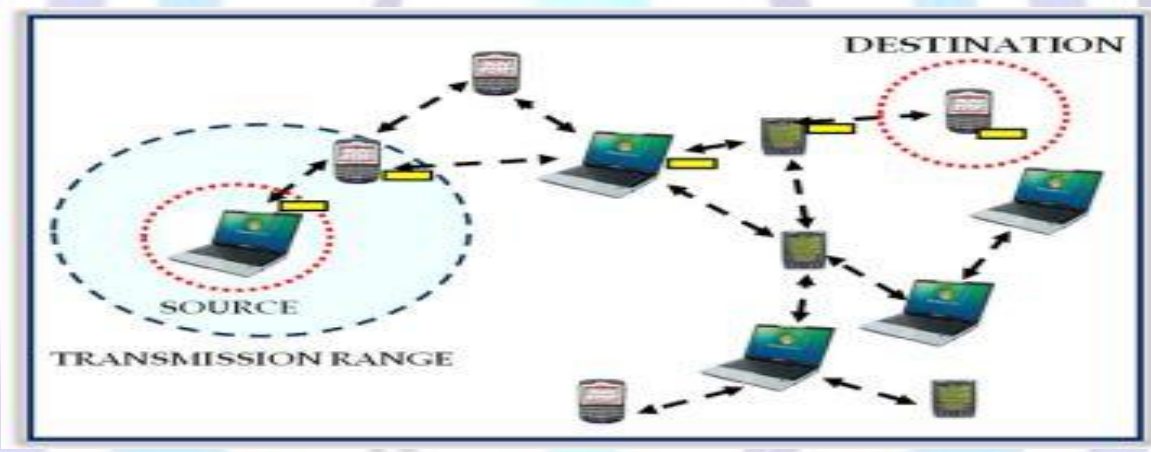

Fig1: Mobile AD HOC Network

routing[11], temporally ordered routing algorithm. In this paper two multipath routing protocols have been discussed: NCPR, QAMR.

\section{NCPR}

NCPR is neighbor coverage based probabilistic rebroadcast protocol[12]. NCPR has been proposed for reducing the routing overhead in MANETs. It offers a combined advantage of two mechanisms:

i. neighbor coverage knowledge and

ii. Probabilistic mechanism.

The working of NCPR can be listed in following steps:

Step 1 deals with the calculation of rebroadcast delay. In Second step, the rebroadcast probability is calculated.

Rebroadcast delay gives us the forwarding order of nodes. The node, with more common neighbors with the previous nodes, has lower delay. To calculate rebroadcast delay the upstream coverage ratio is used.

The calculation of the upstream coverage ratio involves the computing the uncovered neighbor set (UCN) as described by the formula :

$$
U\left(n_{i}\right)=N\left(n_{i}\right)-\left[N\left(n_{i}\right) \cap N(s)\right]-\{s\}
$$

Here, $s$ is the previous node,

$\mathrm{n}_{\mathrm{i}}$ is the node which receives packets form $\mathrm{s}$.

$\mathrm{N}(\mathrm{s}), \mathrm{N}$ (i) are the neighbor set of nodes $\mathrm{s}$ and $\mathrm{n}_{\mathrm{i}}$. 
Rebroadcast delay is used to exploit the neighbor knowledge sufficiently and avoid the channel collisions. A neighbor receiving a RREQ packet, could calculate rebroadcast delay according to the neighbor list in the RREQ packet and its own neighbor list .

Rebroadcast delay $T_{d}\left(n_{i}\right)$ of node $n_{i}$ :

$T_{p}\left(n_{i}\right)=1-\left[N(s) \cap N\left(n_{i}\right)\right] / N(s)$

$T_{d}=$ max delay * $T_{p}\left(n_{i}\right)$

$T_{p}\left(n_{i}\right)$ is delay ratio of node $n_{i}$, max delay is a constant delay I. I is the number of elements in a set. Nodes which have larger rebroadcast delay listen to RREQ packets from the nodes which have lower delay. The uncovered neighbor set is adjusted by a node $n_{i}$ as :

$\mathrm{U}\left(\mathrm{n}_{\mathrm{i}}\right)=\mathrm{U}\left(\mathrm{n}_{\mathrm{i}}\right)-\left[\mathrm{U}\left(\mathrm{n}_{\mathrm{i}}\right) \cap \mathrm{N}\left(\mathrm{n}_{\mathrm{j}}\right)\right]$

Here $n_{j}$ is the node with lower delay and $n_{i}$ with more delay than $n_{j} . n_{i}$ discards the RREQ packet of $n_{i}$ after adjusting $U\left(n_{i}\right)$. Once the rebroadcast delay is calculated, a timer is set. When the timer of rebroadcast delays of node $n_{i}$ expires, node obtains final UCN set. To calculate the rebroadcast probability we need an additional coverage ratio $R_{a}\left(n_{i}\right)$ and the connectivity factor $F_{c}\left(n_{i}\right)$

$R_{a}\left(n_{i}\right)=U\left(n_{i}\right) / N\left(n_{i}\right)$

Rebroadcast probability is the ratio of number of nodes that are additionally covered by this rebroadcast to the total number of neighbors of node $n_{\mathrm{i}}$

Connectivity factor $F_{c}\left(n_{i}\right)=N_{c} / N\left(n_{i}\right)$

Where $\mathrm{N}_{\mathrm{c}}=5.1774 \log \mathrm{n}$,

$\mathrm{n}$ is the number of nodes is the network.

To compute Rebroadcast probability, the following formula is used

$P_{\text {re }}\left(n_{i}\right)=F_{C}\left(n_{i}\right) \cdot R_{a}\left(n_{i}\right)$

After calculating the rebroadcast probability it is checked if random $(0,1)<=P_{r e}\left(n_{i}\right)$ then the request of the previous node is broadcasted else it is discarded.

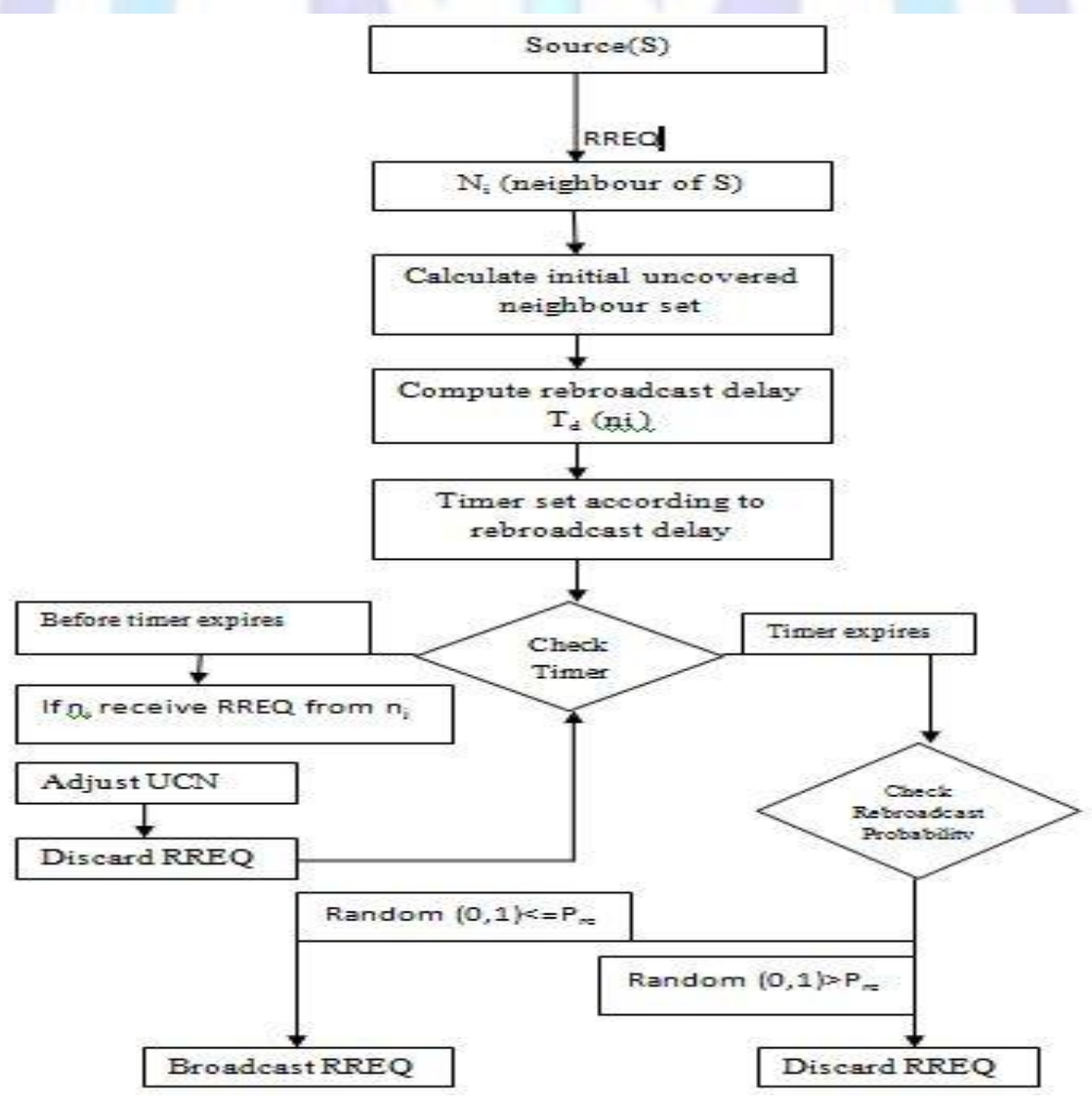

Fig 2: Flow Diagram of NCPR 


\section{QAMR}

QAMR is QoS enabled ant colony optimization based multipath routing protocol[13]. The problem of bandwidth allocation is taken care of by QAMR. For finding a route from source to destination ant like agents (called reactive ants) are generated. BANT, backward ant, are used to return from destination to source.For the route discovery a node checks all its neighbors which fulfill the criterion that the next hop availability (NHA) of a node is greater than the threshold value $\mathrm{NHA}>\mathrm{NHA}_{\text {thr. }}$ FANT(forward ant) is broadcasted only to neighbors fulfilling this criterion. FANT carries the following information:

\section{Source address,}

Destination address,

Sequence number, hop count, previous traversed nodes (in order to traverse loops), bandwidth detail, and start time.

When a FANT reaches the destination, the path preference probability is calculated using the formula $\left(d_{g} b_{g} h_{g}\right)_{I} / \sum_{j \in p i}\left(d_{g}\right.$ $\left.b_{g} h_{g}\right)_{j}$

Where $d_{g} b_{g} h_{g}$ are the goodness values for delay, bandwidth and hop count.

These are calculated using threshold and calculated values of delay, bandwidth and hop count . The path that meets QoS threshold values specified by the user generates a BANT. The destination node waits for a time $T_{w}$ (integer factor of total end-to-end delay $\mathrm{D}_{\mathrm{c}}$ ) to receive all the BANTs. When BANT reaches the intermediate node or the source node, it checks the path preference probability using delay, bandwidth and hop count parameters. BANT are multiple but the path with higher pheromone value is selected for data transmission.

The pheromone value is calculated using the formula $T_{i j}=\left(1+T_{i n}\right) P(k)_{d}$

$P(k)_{d}$ is the path preference probability of $k^{\text {th }}$ path

$\mathrm{T}_{\mathrm{ij}}=\mathrm{T}_{\mathrm{ij}}+$ delta $_{\mathrm{ij}}$

Where $T_{i j}=0.1$ and delta $T_{i j}=0.05$ initially.

QAMR performs better than AODV and ARMAN[14] for the metrics: packet delivery ratio, QOS path success ratio, routing overhead.

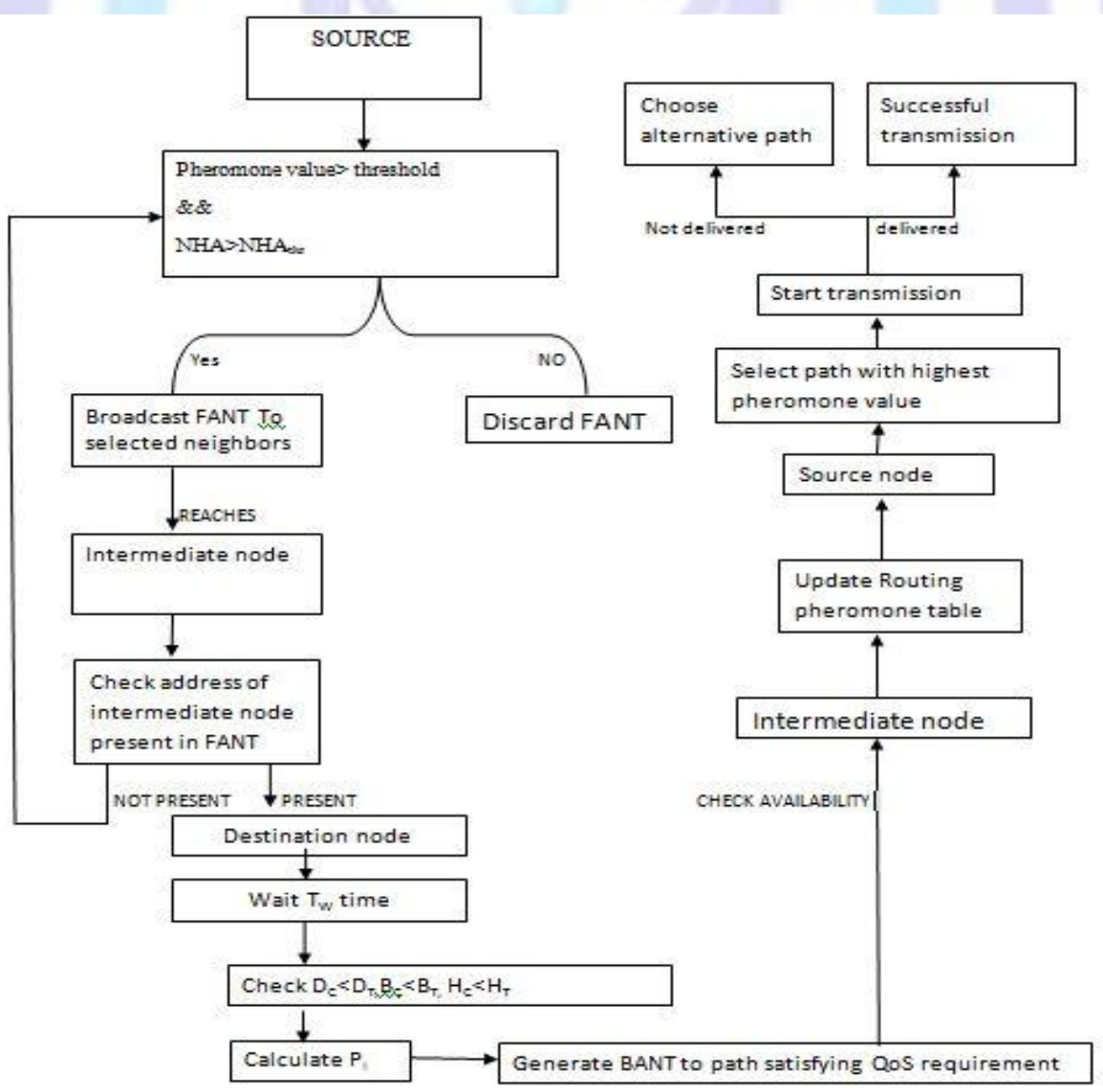

Fig3: Flow chart of QAMR 


\section{Conclusion}

In this paper two multipath routing protocols NCPR and QAMR have been discussed. These protocols use delay, bandwidth, routing overhead as the QoS metrics. NCPR is an improvement which uses AODV as its base protocol. QAMR is an ant colony optimization based protocol.

Table below shows a summarized form of these two protocols:

Table 1: Summary of QAMR and NCPR

\begin{tabular}{|l|l|l|}
\hline Protocol & QAMR[13] & NCPR[12] \\
\hline QOS Metrices & Delay/ Bandwidth & Routing overhead \\
\hline Base protocol & ACO[15] & AODV \\
\hline $\begin{array}{l}\text { Multiple Route } \\
\text { Support }\end{array}$ & Yes & Yes \\
\hline $\begin{array}{l}\text { Routing } \\
\text { overhead }\end{array}$ & Higher than AODV & - \\
\hline Loop free & Yes & Yes \\
\hline End to end delay & Higher than AODV & - \\
\hline
\end{tabular}

\section{References}

[1] Pravin Ghosekar, Girish Katakar, Pradip Ghorpade, "Mobile Ad Hoc Networking: Imperatives and Challenges", IJCA special issue on " Mobile ad hoc networks" ,MANETs 2010

[2] Jeroen Hoebeke, Ingrid Moerman, Bart Dhoedt and Piet Demeester, "An overview of Mobile AD HOC Networks: Applications and challengenges." Department of Information Technology(INTEC), Belgium, session 4

[3] Aleksi Penttinen,"research on ad hoc networking: current activity and future directions", finland

[4] Seema, Dr. yudhvir singh, vikas siwach, "Quality Of Service in MANET", International Journal of Innovations in engineering and technology (IJIET), October- 2012

[5] Ricordo Lent, "Linear QoS Goals of Additive and Concave Metrics in Ad-hoc Cognitive Packet Routing", volume 36, NO.6, pp: 1255-1260, December 2006

[6] Ipsita Panda "A Survey on Routing Protocols of MANETs by Using QoS Metrics " International journal of advanced Research in computer science and software engineering, volume2, October 2012

[7] Corson S, Macker J , "Mobile Ad hoc Networking (MANET) Routing Protocol Performance Issues and Evaluation Considerations rfc2501",January 1999.

[8] Charles E. Perkin , Elizabeth M. Royer "Ad-hoc On Demand Distance Vector Routing” , Sun Microsystems Laboratories ,Menlo Park, CA 94025.

[9] D. B. Johnson and D. A. Maltz, "Dynamic Source Routing in Ad Hoc Networks", Mobile Computing, T. Imielinski and H. Korth, Eds., Kulwer Publ., 1996, pp. 152-81.

[10]G.Lavanya and A. Ebenezer Jeyakumar, "An Enhanced Secured Dynamic Source Routing Protocols for MANETs", International Journal of Soft Computing and Engineering, vol X, pp:135-140, September 2011

[11] Neerja Khatri and Arvind Kumar, "Analysing Performance of AODV Routing protocol in mobile Ad-hoc networks: A survey", International Journal of Engineering Research and Technology, vol1,issue3, pp:1-5, May 2012

[12] Xin ming zhang et.al " a neighbor coverage based probalistic rebroadcast for reducing routing overhead in mobile Adhoc networks", IEEE transactions on mobile computing, vol 12, no 3,2013 
[13] P.venkata krishna et al. " QoS Enabled Ant Colony Based Multipath Routing for Mobile AD HOC Networks" IET communications, vol 6 issue 1.pp:76-83

[14] Deepalakshmi, P. Radhakrishnan, "Ant Colony Based Routing Algorithm for Mobile Ad-hoc Networks", International Journal Recent Trends Engg., pp:459-462, 2009

[15] Sudarshan D Shrikande, Rambabu A Vatti, "ACO based routing algorithm for ad hoc network (WSN, MANETs): A Survey", International Conference On Communication Systems and Network Technologies, 2013

\section{Author Biography}

\section{Roopali Garg}

Roopali Garg is Coordinator of department of Information Technology Engineering at UIET, Panjab University, Chandigarh. She has an experience of 10 years in academics. She has done M. tech in Electronics and B. Tech in Electronice \& Electrical Communication from Punjab Engineering College. She has been awarded Administrator's Gold medal by Chandigarh Administration in 2000 for her supreme performance in curricular, co- curricular and extra- curricular activities. There are more than twenty research papers to her credit which have been published in good indexed international journals and presented in reputed international conferences. Her focussed research area is Wireless communication and has guided more than a dozen M. thesis in this area.

\section{Guneet Kaur}

Guneet Kaur is a Research Scholar of department of Information Techology at UIET, Panjab University, Chandigarh. She is persuing her M.E. in Information and technology from UIET, Panjab University, Chandigarh and has done her B.Tech in Information Technology from D.A.V.I.E.T. Her main research interests are in ad hoc networks and wireless networks and currently involve routing, improving QoS in Mobile Ad hoc Networ.

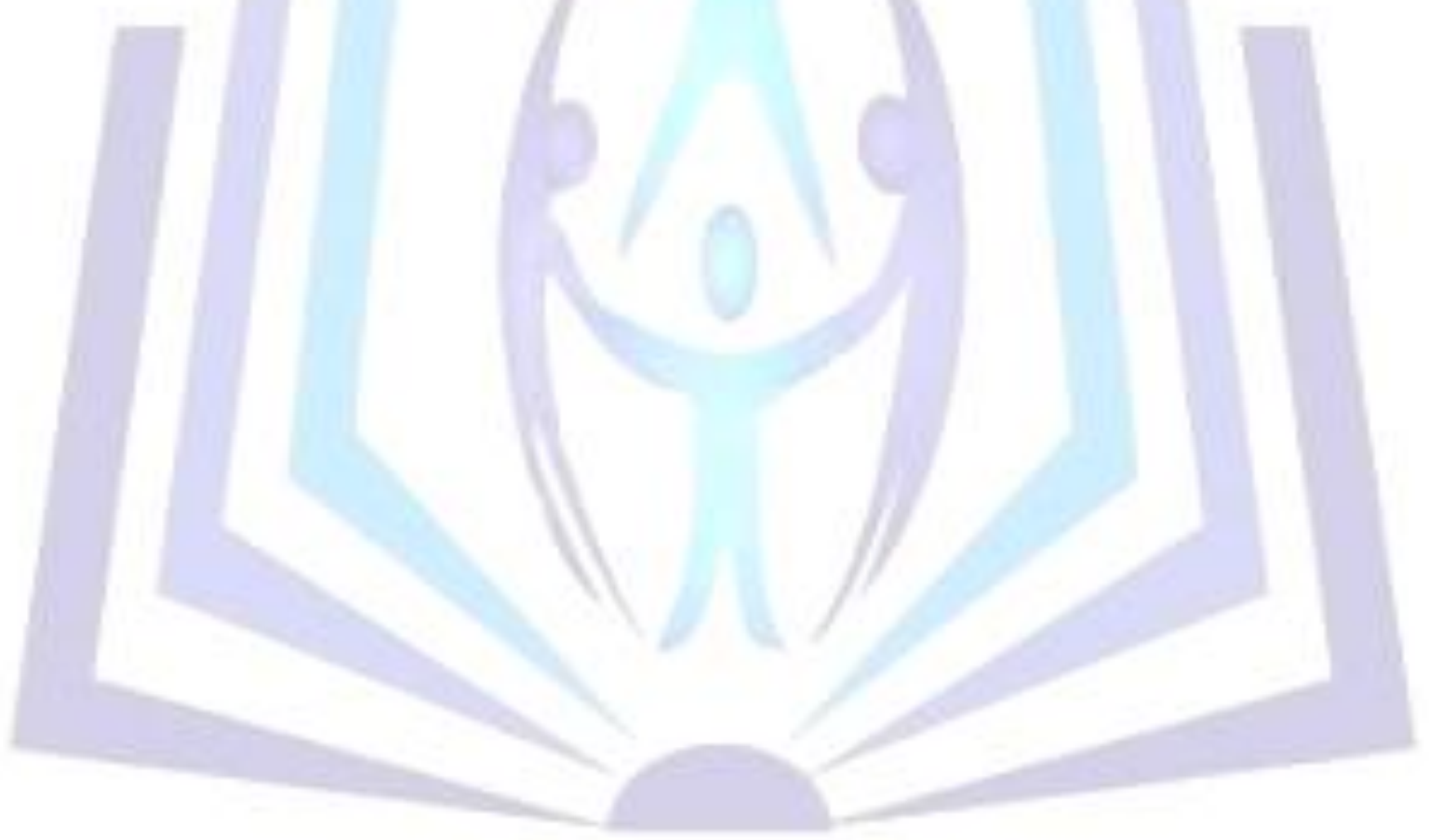

